\title{
Contract System Pertaining to the Employment of Permanent Secretaries in the Public Service in Zambia
}

This chapter uses empirical data based on interviews of key informants and document sources to examine the contract system of employment of senior public service officers in Zambia. The aim is to understand the Zambian public sector reforms and to gather evidence to ascertain the success or otherwise of the implementation of contract employment as part of the new public management experiment in developing countries. The chapter examines the background to the reform of the position and conditions of service of permanent secretaries, introduction of contracts of employment to the senior public service and conditions of service for permanent secretaries. It then analyses entitlements in the employment contracts for the permanent secretary, room for expression of leadership by the permanent secretary, management models and frameworks which have been used in the reform, value for money and lessons learned.

\section{Background to the reform of the position and conditions of service of permanent secretaries}

From a briefing paper on the reform of the position and conditions of work of permanent secretaries prepared by the Zambian Cabinet Office in 2005, a number of interesting characteristics of the changes could be isolated. The briefing paper was in response to a 2004 consultancy report regarding the design of a performance-based contract system for permanent secretaries. The cabinet secretary set out the contemporary perceptions of the role and performance of permanent secretaries and made a candid assessment of the institution of permanent secretary. It was acknowledged that the original concept of 'permanent secretary' emphasised the permanency of this position and was also designated as one that should be occupied by the senior civil servant. In Zambia, historically, most office holders were career civil servants who had gone through what the cabinet secretary referred to as the 'scheme of service' and therefore had developed a mastery of civil service rules and procedures as well as possessing professional and technical skills and competencies. Permanent secretaries 
were expected to possess capabilities required for, among other things, interpreting the policy agenda of the political executive, providing technical guidance in policy formulation and implementation, and galvanising the contributions of public service personnel to deliver according to set objectives and achieve high levels of efficiency and effectiveness. These certainly reflect the required qualities of leadership in the Westminster-Whitehall model of administrative management, which have been put under strain in recent reforms.

The review also noted that in the early years after independence, Zambia followed this tradition and embarked on a vigorous programme of indigenisation by developing nationals for senior positions in the public service. Indeed, A L Adu had in his book The Civil Service in Commonwealth Africa (Adu, 1962) acknowledged the dearth of skilled personnel in the period of terminal colonialism not only in Zambia, but also in other Southern African countries. The Cabinet brief was therefore accurate in its assessment of the evolution of the senior public service in Zambia. The pursuit of the Kaunda administration in the heady days of independence created a discernible career progression path and added prestige to the appointments system, as it was based on the merit principle. Changes were introduced, however, with the onset of the Second Republic, which led to greater reliance being placed on political expediency. This practice, the cabinet secretary noted, had affected the position of senior public service personnel, especially at permanent secretary level, which had become very tenuous as a number of appointments had been made outside the system. The approach resulted in a number of consequences, the key implications of which included those listed below.

1. Values such as professionalism, independence, integrity, political impartiality, transparency and service to the public, associated with the merit principle applied to appointments, are often sacrificed.

2. There is no clearly defined set criteria that could be applied to explain the basis of some of the appointments made in terms of qualifications, experience and overall suitability of candidates.

3. Distortion of career progression opportunities in the public service as lower ranked personnel cannot meaningfully aspire to senior positions on the basis of performance.

4. An impression is created that appointments are a form of reward by the political executive to party loyalists - a situation that also compromised the political impartiality of those who were appointed.

5. A perception is created that the position of permanent secretary requires no particular skills, experience or knowledge of the operations of line ministries and the public service' (Zambia, 2005). 


\section{Introduction of contracts of employment to the senior public service}

\section{Conditions of service for the permanent secretary}

How did the reform under President Mwanawasa purport to address the above listed challenges? A contract system was introduced in 2003 and was managed by the Office of the President through the cabinet secretary and head of the Public Service. But this was not a performance contract in spite of the fact that a performance management system had been introduced in the public service of Zambia. Characteristically, a normal letter of appointment was issued by the cabinet secretary, which indicated that His Excellency the President has appointed a particular individual as permanent secretary in accordance with the provisions of Article 44 (2) of the Constitution of Zambia and in exercise of the powers vested in him by Section 9 of the Public Service Act, chapter 259 of the Laws of Zambia. The appointment letter normally states that the permanent secretary is on a contract of employment, and stipulates the salary grade including the basic salary, a gratuity pegged at 100 per cent of each completed year served, but paid at the end of the contract. The leave entitlement of the permanent secretary was three-and-half days per month, adding up to 42 days in a year. The specific definition of functions and accountabilities of permanent secretaries are set out in two documents, namely the Letter of Appointment and the Cabinet Handbook which was produced in Lusaka in July 2002.

In 2005, the salary of a permanent secretary was generally in the range of between 45 million kwacha (ZK) and ZK54 million per annum. In comparison, most heads of statutory boards were paid salaries of not less than ZK120 million per annum (or ZK10 million per month), which is almost three times what a permanent secretary received. Heads of statutory boards were therefore compensated according to job worth and market comparability, while the permanent secretary was not (Management Development Division, 2005). ${ }^{1}$ From the interviews conducted with some of the serving permanent secretaries in Zambia in July 2008 it was clear that the Permanent Secretary-Head of Statutory Board salary disparity had not been addressed as yet, and that this was a source of discontent and demotivation for the permanent secretary. The implication of this, according to the interviews, is that the low-paid permanent secretary lacked the moral fortitude and incentive to demand compliance from the highly paid subordinates who run the statutory boards, and this has remained a significant management issue which the Government of Zambia needed to resolve.

With regard to the length of contract, the original contemplation was for the adoption of a five-year renewable contract. However, three-year contracts have become the norm and, as at August 2008, renewal was significantly based on subjective criteria because the Government of Zambia was still examining the prospect of introducing performance-based contracts, which purportedly would be accompanied by measurement instruments for assessing the work of permanent secretaries. The Independent Management Consulting Services Limited (IMCS) of Zambia had in 
2004 been contracted to assess the current employment contract system and design performance-based contracts for permanent secretaries. However, revelations from the interviews seemed to indicate that the recommendations of the consultancy had not been put into action almost four years after.

\section{Entitlements in the employment contracts for the permanent secretary}

A reading of the Cabinet Handbook 2002 shows that, in spite of their changed employment status, permanent secretaries are still considered as public officers and are bound by all the codes of conduct of the civil service and rules of confidentiality. Relieved of almost all the powers of appointment as a chief executive, the permanent secretary has been given authority to appoint one officer - the cabinet liaison officer (CLO) - who is responsible for co-ordinating all Cabinet business within the ministry, including the preparation and handling of Cabinet documents. This power of appointment is significant because the CLO, as representative of the permanent secretary, retains day-to-day contact with the Policy and Co-ordination Division at the Office of the President, and he/she also provides the secretariat for meetings of inter-ministerial committees of officials. In Zambia, permanent secretaries are the administrative heads of ministries, provinces and divisions. There are in total 42 permanent secretaries, as Zambia has 22 ministries and nine administrative regions and the Ministry of the Presidency has as many as four permanent secretaries. However, where there is more than one permanent secretary, only one of them is appointed as controlling officer, in terms of financial management of the ministry.

The permanent secretary is entitled to a basic salary, vacation leave of 42 days in a year and a vacation allowance, has access to official transport, and a gratuity of 100 per cent of gross salary, which is taxed at 35 per cent. However, there were some permanent secretaries who took issue with the grading of permanent secretaries on a flat scale, in the sense that they thought inadequate recognition was given to those who handle larger portfolios. This meant that there were no incentives for those permanent secretaries who managed the big ministries and they were treated in the same way as those who manage small ministries.

\section{To whom are permanent secretaries responsible?}

The post of permanent secretary is a constitutional post and it enjoys constitutional protection. The Cabinet Handbook 2002 notes that the minister and the permanent secretary are jointly responsible for the performance of their ministry. The permanent secretary is, however, responsible for the day-to-day operations and administration and for dealing with 'all civil service matters in their ministries, provinces and divisions' (Cabinet Handbook 2002: Section 10.9). Similarly, permanent secretaries are responsible to the Ministry of Finance in their exercise of financial control. In relation to that role, they may be called upon occasionally to answer queries from the 
Public Accounts Committee of Parliament, and will be liable for prosecution and surcharge for any unauthorised, irregular of wasteful expenditure by the ministry or for loss of revenue resulting from financial irregularity or serious inefficiency. The conceptualisation of the roles of minister and permanent secretary in the Cabinet Handbook is interesting, in the sense that nowhere is it written that the permanent secretary is responsible to the minister. In fact, they are jointly responsible for the policy and administrative output of the ministry and both are responsible to the President. This leads to the archaic (and much resented) practice in which the President can dispense with the services of a permanent secretary at press conferences, even before the notice of dismissal is received by the relevant permanent secretary.

\section{Room for expression of leadership by the permanent secretary}

From the interviews conducted with senior public service officers, the partial collegial nature of the relationship between the permanent secretary and ministers is helpful. There seemed to be divided opinion regarding the availability of revenues to the permanent secretary for the administration of the ministry. On balance, however, there was a convergence of opinion around the belief that the Ministry of Finance was now getting on top of its business and was making disbursements of the budget on time for use by other ministries. By far the most important obstacle to the expression of leadership by the permanent secretary was the issue of the unceremonious dismissals announced at press conferences by the president. This issue represented a grave concern to all the permanent secretaries interviewed, who felt that such issues about people's employment should be treated with delicacy.

The hand of the permanent secretary is, however, strengthened in his/her expression of leadership in the control of the finances of the ministry. The Cabinet Handbook 2002, Section 10.20, is emphatic that 'permanent secretaries have a duty to refuse, in writing, to act in a manner that is financially irregular, if requested or directed by the minister', and 'permanent secretaries should carry out their minister's directives on financial matters only if the instructions are issued in writing and indicate that the minister accepts responsibility for the proposed course of action' (Section 10.21). In the event of such a situation arising, the permanent secretary is obliged to report it to the minister responsible for finance and the Auditor-General, who may then consider reporting the matter to the Public Accounts Committee of Parliament with copies to the secretary to the cabinet.

\section{Management models and frameworks which have been used in the reform}

Information obtained through the interviews seems to suggest that there is not a single overarching management model imposed at the national level. Decentralised management is practised, however, as the country is divided into nine administrative regions or provinces and there is a permanent secretary at each region, as well 
as a provincial co-ordinating committee. Zambia also seems to have big government in that the country has 42 permanent secretaries. Some ministries and departments have multiple permanent secretaries. The Ministry of Agriculture has two; Ministry of Finance has three and the Cabinet Office has four. The secretary to the treasury is the one who appoints permanent secretaries as controlling (accounting, in other jurisdictions) officers, under the Finance and Administration Act.

Similarly, performance appraisal has been introduced for the rank and file, but it is not applied universally across all ministries, and as a result of the absence of an overarching management model nationally, there is room for innovation and experimentation by individual permanent secretaries. For example, the current permanent secretary for science, technology and vocational training was appointed into the public service from the University of Zambia. He was a statistician, and he noted in the interview that his professional background has proved useful because he has been able to introduce monitoring and evaluation frameworks in his ministry. It was through his consultancy work in statistics to the government that he was recommended for appointment as permanent secretary.

Another noteworthy example of personal initiative was recorded with the permanent secretary for justice, who had previous private practice as a lawyer in the banking sector, but had been appointed to the public service as a deputy director and had worked in the system for about fifteen years and became a permanent secretary in 2003. Upon her appointment as permanent secretary she updated the policies and records and evaluated her staff on a yearly basis and also involved them in drawing up the budget. Under her watch Zambia took part in the African Peer Review Mechanism and wrote reports on the Rights of the Child and Report to the African Charter on Human Rights. The permanent secretary for justice also indicated that she wrote the 'State of Human Rights Report' when she was deputy director of the ministry and that endeared her to donors, who supported the institutionalisation of the report writing. The same activity is now budgeted for and fully funded by her ministry. Strategic planning was another tool that had been tried at the Ministry of Justice to great advantage. The permanent secretary noted that her efforts had been acknowledged internationally in that Zambia has been voted to UN Human Rights Council.

\section{Value for money}

From a systemic perspective, Zambia theoretically has a laudable system. However, the bane of Zambian governance is lack of implementation of the ideas suggested by the Independent Management Consulting Service about how to install a performance-based contract for permanent secretaries, paid for and accepted by Cabinet, but about which little had been done, as at the time of the research in July 2008. There were young directors at the Cabinet Office who in conversations indicated that they would not want to be permanent secretary under the current 
system because of the lack of an objective criterion for measuring and rewarding the permanent secretary, and because of the subjectivity and uncertainty surrounding the security of contracts. Apart from one positive review of the current system, a majority of those who were interviewed noted that the contract system was still a work in progress and that its full value will be reaped when a performance contract has been established and the operating environment including a changed budgetary allocation system has been created.

\section{Conclusion and lessons learned}

The reform of public management in Zambia since the early 2000s has had an important element which dealt with human resource capabilities and terms and conditions of work of senior public servants - in particular, permanent secretaries with the view to establishing a senior executive service along the lines of New Zealand. The fieldwork revealed that there are multiple approaches to appointing permanent secretaries, but the president of the republic is the appointing authority. The two main ways of appointing a permanent secretary include headhunting from the private sector or academia and hierarchical appointment by way of appointing people from the public service based on seniority and talent.

From the fieldwork, interviews and discussions with public officials in Zambia, it was realised that there was a mood for change and fuller implementation of reforms proposed for better managing the employment of permanent secretaries. Employment contracts have been introduced to replace the permanent and pensionable terms under which the senior public service officers served. An equally valuable document in the form of a Cabinet Handbook has been published, which seem to embody the essentials of contemporary good governance practice. This was intended to support institutionalisation of the new system. However, the lack of objective measures of performance of permanent secretaries and the lack of performance contracts seem to be of grave concern to the current cohort as well as up-and-coming directors the pool from which future permanent secretaries could be drawn. The practice of dismissal of permanent secretaries by press conference was resented, yet it seemed to represent an issue which could be easily addressed by government without any cost. Finally, the Zambian system seems to require local champions who can manage system-wide performance management system across government and a Cabinet Office that is well equipped to evolve an evaluation system for the contracts and manage it on a regular basis.

\section{Notes}

1. Management Development Division, Cabinet Office, Office of the President (2005). 
